\title{
Assembly of cellulases with synthetic protein scaffolds in vitro
}

\author{
Ting Yu, Xin Gao, Yuhong Ren ${ }^{*}$ and Dongzhi Wei
}

\begin{abstract}
Background: Enzymatic cascades in metabolic pathways are spatially organized in such a way as to facilitate the flow of substrates. The construction of artificial cellulase complexes that mimic natural multienzyme assemblies can potentially enhance the capacity for cellulose hydrolysis. In this study, an artificial cellulase complex was constructed by tethering three cellulases to a synthetic protein scaffold.

Results: Three pairs of interacting proteins were selected and characterized. The artificial protein scaffolds were constructed by fusing three interacting proteins. Cellulases were tethered to these synthetic scaffolds in different orders. The optimal assembly resulted in a 1.5-fold higher hydrolysis of cellulose than that achieved by unassembled cellulases.

Conclusions: A novel artificial protein scaffold was constructed and used to assemble three cellulases. The resultant increase in enzymatic activity suggests that this can be used as a strategy for enhancing the biocatalytic capacity of enzyme cascades.
\end{abstract}

Keywords: Multienzyme; Assembly; Scaffold; Cellulose

\section{Background}

Multienzyme pathways in living systems comprise cascades in which enzymes are tethered together into assemblies that facilitate substrate flow between components, limit the diffusion of intermediate metabolic products, and increase the yield from sequential reactions [1,2]. There have been various attempts to produce multienzyme assemblies in vitro, including by gene fusion, protein or DNA scaffold construction, and chemical modification [3]. Although the simplest way is by enzyme fusion, this often results in loss of enzymatic activity or formation of inclusion bodies [4], while chemical modification can also impair enzymatic activity [5]. Moreover, the high cost of generating DNA scaffolds makes this approach infeasible on a large scale [6,7].

Protein scaffolds are an attractive strategy for bringing together enzymes. A 77-fold enhancement in product concentration was observed in an assembly of three mevalonate biosynthetic enzymes with a protein scaffold composed of metazoan signaling proteins [8]. In another study, a selfassembled enzyme complex using cellulosome achieved a

\footnotetext{
* Correspondence: yhren@ecust.edu.cn

State Key Laboratory of Bioreactor Engineering, East China University of Science and Technology, 130 Meilong Rd, Shanghai 200237, People's
} Republic of China 13.4-fold increase in reaction rate [9], while a proliferating cell nuclear antigen-based assembly of P450 with ferredoxin and ferredoxin reductase showed high catalytic activity [10]. The protein scaffolds used in these studies were limited to metazoan signaling proteins and cellulosome components [11-14], which may not be amenable to all types of enzyme cascades. As such, there is an ongoing need for novel and different types of protein scaffolds.

Cellulose is the most abundant renewable resource on Earth and plays a significant role in biofuel production [15]. Cellulose is broken down into oligosaccharides by endoglucanase (EG) and exoglucanase $(\mathrm{CBH})$ before $\beta$ glucosidase (BGL) hydrolyzes cellobiose into glucose [16]. EG, CBH, and BGL are enzymes in the cellulose degradation pathway that act synergistically; coexpressing these enzymes improves the efficiency of cellulose degradation [17]. It was hypothesized that a highly ordered assembly containing the three cellulases would enhance their activities and thereby increase cellulose hydrolysis. Therefore, CelccA (EG), CelccE (CBH), and Cel2454 (BGL) were selected as a model system for protein scaffold-mediated assembly strategy.

In this study, considering the correct expression and assembly of proteins, three pairs of interacting proteins

\section{Springer}


(IPA/IPa, IPB/IPb, and IPC/IPc) from E. coli $\mathrm{K} 12$ [18] were selected to construct a protein scaffold for three cellulases - namely, CelccA (EG), CelccE (CBH), and Cel2454 (BGL) (Figure 1). The enzymes were arranged in different orders and the effect on activity was investigated. The multienzyme complex in best order was characterized in detail and compared with the unassembled components.

\section{Methods}

\section{Strains and medium}

Escherichia coli $\mathrm{DH} 5 \alpha$ was used for cloning, and E. coli BL21 (DE3) was used for protein expression. Cells were cultured in Luria-Bertani (LB) medium (10.0 g/l tryptone, $5.0 \mathrm{~g} / \mathrm{l}$ yeast extract, $10.0 \mathrm{~g} / \mathrm{l} \mathrm{NaCl}$ ) supplemented with either $100 \mathrm{mg} / \mathrm{l}$ ampicillin or $50 \mathrm{mg} / \mathrm{l}$ kanamycin.

\section{Plasmid construction}

PCR primer sequences are listed in Table 1. All plasmid sequences were validated by sequencing. To generate the pET21a-IPA plasmid, the IPA gene (GenBank accession no. EU899769.1) was amplified from E. coli K12 genomic DNA using the IPA-F/IPA-R primer pair. The PCR product was digested with $\mathrm{NdeI} / \mathrm{XhoI}$ and ligated into pET21a digested with the same restriction enzymes. Similarly, plasmids pET21a-IPa, pET21a-IPB, pET21a-IPb, pET21a-IPC, and pET21a-IPc were constructed by amplifying the DNA sequences of $I P a, I P B, I P b, I P C$, and $I P C$ (GenBank accession nos. EU895384.1, EU8971IPC.1, AB9163IPA.1, EU893769.1, and EU891369.1, respectively) using the primer pairs IPa-F/IPa-R, IPB-F/IPB-R, IPb-F/ IPb-R, IPC-F/IPC-R, and IPc-F/IPc-R, respectively. Plasmids pET28a-celCCA, pET28a-celCCE, and pET28acel2454 were constructed by amplifying the DNA sequences of celCCA, celCCE, and cel2454, respectively (GenBank accession nos. M93096.1, M87018.2, and ACL76783.1, respectively), from the genomic DNA of Clostridium cellulolyticum DSM 5812 using the primer pairs A-F/ A-R, E-F/E-R, and 4-F/4-R, respectively $[19,20]$.

Plasmid pET28a-IPaA had an expression cassette containing IPa and celCCA at the $\mathrm{N}$ and $\mathrm{C}$ termini, respectively. A DNA fragment encoding IPa was amplified with the primer pair IPaA-F/IPaA-R and cloned into pET28acelCCA by Seamless Cloning [21]. Plasmid pET28a-AIPa containing celCCA and $\mathrm{IPa}$ at the $\mathrm{N}$ and $\mathrm{C}$ termini, respectively, was generated with the primer pair AIPa-F/ AIPa-R. Plasmid pET28a-IPbE containing IPb and celCCE at the $\mathrm{N}$ and $\mathrm{C}$ termini, respectively, was generated with primer pair IPbE-F/IPbE-R. Plasmid pET28a-EIPb containing celCCE and $\mathrm{IPb}$ at the $\mathrm{N}$ and $\mathrm{C}$ termini, respectively, was constructed with primer pair EIPb-F/EIPb-R. Plasmid pET28a-IPc4 containing IPc and cel2454 at the N and $\mathrm{C}$ termini, respectively, was generated with primer pair IPc4-F/IPc4-R. Plasmid pET28a-4IPc containing cel2454 and IPc at the $\mathrm{N}$ and $\mathrm{C}$ termini, respectively, was constructed with primer pair 4IPc-F/4IPc-R.

Plasmid pET21a-ScafBAC had an expression cassette containing IPA flanked by IPB and IPC at the N and $\mathrm{C}$ termini, respectively. The DNA fragments encoding IPB, IPA, and IPC were amplified with the primer pairs ScafBAC-F1/IPB-R, ScafBAC-F2/IPA-R, and ScafBAC-F3/ ScafBAC-R, respectively. The three fragments were cloned into pET21a by Seamless Cloning. Plasmid pET21aScafABC was constructed using primer pairs ScafABC-F1/ IPA-R, ScafABC-F2/IPB-R, and ScafABC-F3/ScafABC-R, and plasmid pET21a-ScafBCA was generated using primer pairs ScafBAC-F1/IPB-R, ScafABC-F3/IPC-R, and ScafBCA-F/ScafBCA-R.

\section{Protein expression and purification}

Recombinant proteins were precultured overnight at $37^{\circ} \mathrm{C}$ in LB medium supplemented with appropriate antibiotics. The cultures were inoculated in fresh LB medium containing antibiotics and incubated at $37^{\circ} \mathrm{C}$ until the optical density at $600 \mathrm{~nm}$ reached 0.8 . The cultures were then cooled to $18^{\circ} \mathrm{C}$, and isopropyl- $\beta$-D-thiogalactopyranoside was added to a final concentration of $0.1 \mathrm{mM}$. After $20 \mathrm{~h}$, cells were harvested by centrifugation for $10 \mathrm{~min}$ at $8,000 \mathrm{rpm}$ and $4^{\circ} \mathrm{C}$, resuspended in $20 \mathrm{mM}$ phosphate-buffered saline (PBS; pH 7.0), and disrupted by sonication on ice. Cellular debris was removed by centrifugation for $40 \mathrm{~min}$ at 11,000 rpm. Proteins were purified using a HisTrapFF column (GE Healthcare, Waukesha, WI, USA), and protein concentration was determined by the Bradford method.

\section{Biolayer interferometry}

Binding affinities between proteins were measured by biolayer interferometry (Octet QKe; Fortebio, Menlo Park, CA, USA), which detects changes in mass (protein density)

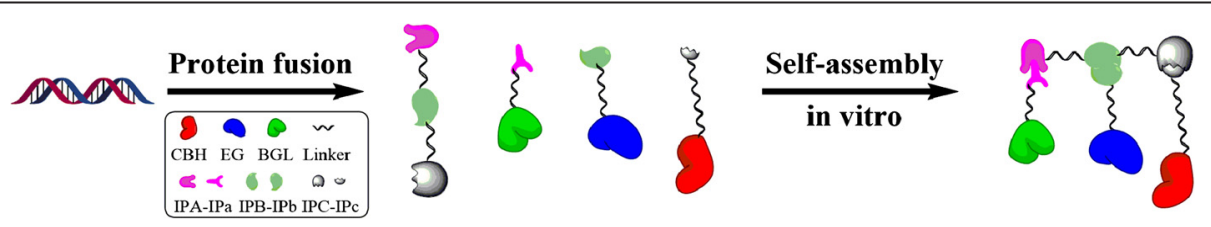

Figure 1 Schematic representation for assembly of cellulases on a protein scaffold. Three cellulases (CBH, EG, BGL) and three pairs of interaction proteins (IPA-IPa, IPB-IPb, IPC-IPC) were used for the assembly. 
Table 1 Primers used in this work

\begin{tabular}{|c|c|}
\hline Name & Sequence \\
\hline$\overline{\mathrm{IPA}-\mathrm{F}}$ & GGAATTCCATATGATGCGAATTCTGGCTATC \\
\hline IPA-R & CCGCTCGAGTTCTTTGCCCGGAAGTTTC \\
\hline $\mathrm{IPa}-\mathrm{F}$ & GGAATTCCATATGATGCGTGTACTGGGTATTG \\
\hline IPa-R & CCGCTCGAGCGCAGCCGGTAACTCCGCC \\
\hline IPB-F & GGAATTCCATATGATGAACGATGAAATGAAAG \\
\hline IPB-R & CCGCTCGAGGGCTTTATTCTGACGCCAC \\
\hline $\mathrm{IPb}-\mathrm{F}$ & GGAATTCCATATGATGGCAAGATATTTGGG \\
\hline $\mathrm{IPb}-\mathrm{R}$ & CCGCTCGAGCTTGGAGTAAAGCTCGAC \\
\hline IPC-F & GGAATTCCATATGATGACTGACAAAATGC \\
\hline IPC-R & CCGCTCGAGCGCTTCAATGGCAGCAC \\
\hline IPc-F & GGAATTCCATATGATGGCAACACGAATTG \\
\hline IPc-R & CCGCTCGAGTGGAATCAGCAGGCTGG \\
\hline$A-F$ & GGAATTCCATATGTATGATGCTTCACTTATTCCG \\
\hline$A-R$ & CCGCTCGAGGTTGCTTGGAAGCTTAC \\
\hline $\mathrm{E}-\mathrm{F}$ & GTGCCGCGCGGCAGCCATATGATAGGACAAGCATTTGC \\
\hline $\mathrm{E}-\mathrm{R}$ & GTGGTGGTGGTGGTGCTCGAGAGTTGGAGGAGTCACTGACCC \\
\hline $4-\mathrm{F}$ & GGAATTCCATATGCAATACGATCAGATAGATAAA \\
\hline $4-\mathrm{R}$ & CCGCTCGAGCAGAGCAAGAGCTATAG \\
\hline IPaA-F & GTGCCGCGCGGCAGCATGCGTGTACTGGGTATTGAAACTTC \\
\hline IPaA-R & AAGTGAAGCATCATACGATCCGCCACCGCCAGAGCCACCTCCGCCCGCAGCCGGTAACTCCG \\
\hline AlPa-F & AAGCTTCCAAGCAACGGCGGAGGTGGCTCTGGCGGTGGCGGATCGCGTGTACTGGGTATTG \\
\hline AlPa-R & GTGGTGGTGGTGGTGCGCAGCCGGTAACTCCGCCAGCGGC \\
\hline IPbE-F & GTGCCGCGCGGCAGCATGGCAAGATATTTGGGTCCTAAGC \\
\hline $\mathrm{IPbE}-\mathrm{R}$ & AAATGCTTGTCCTATCGATCCGCCACCGCCAGAGCCACCTCCGCCCTTGGAGTAAAGCTCG \\
\hline $\mathrm{EIPb}-\mathrm{F}$ & GTGACTCCTCCAACTGGCGGAGGTGGCTCTGGCGGTGGCGGCAAGATATTTGGGTCCTAAGC \\
\hline $\mathrm{EIPb}-\mathrm{R}$ & GTGGTGGTGGTGGTGCTTGGAGTAAAGCTCGACGATCAGGTG \\
\hline IPC4-F & GTGCCGCGCGGCAGCATGACTGACAAAATGCAAAGTTAG \\
\hline IPC4-R & TATCTGATCGTATTGCGATCCGCCACCGCCAGAGCCACCTCCGCCCGCTTCAATGGCAGCAC \\
\hline $4 \mathrm{PC}-\mathrm{F}$ & ATAGCTCTTGCTCTGGGCGGAGGTGGCTCTGGCGGTGGCGGATCGACTGACAAAATGCAAAG \\
\hline $4 I P C-R$ & GTGGTGGTGGTGGTGCGCTTCAATGGCAGCACGCAATTITTC \\
\hline ScafBAC-F1 & TAAGAAGGAGATATAAACGATGAAATGAAAGGTAAAAGCGGC \\
\hline ScafBAC-F2 & CGTCAGAATAAAGCCGGCGGAGGTGGCTCTGGCGGTGGCGGATCGCGAATTCTGGCTATCG \\
\hline ScafBAC-F3 & CTTCCGGGCAAAGAAGGCGGAGGTGGCTCTGGCGGTGGCGGATCGACTGACAAAATGCAAAGTI \\
\hline ScafBAC-R & GTGGTGGTGGTGGTGCTCGAGCGCTTCAATGGCAGCACGC \\
\hline ScafABC-F1 & TAAGAAGGAGATATACGAATTCTGGCTATCGATACCGCGACAGAGGCCTGCTC \\
\hline ScafABC-F2 & CTTCCGGGCAAAGAAGGCGGAGGTGGCTCTGGCGGTGGCGGATCGAACGATGAAATGAAAGG \\
\hline ScafABC-F3 & CGTCAGAATAAAGCCGGCGGAGGTGGCTCTGGCGGTGGCGGATCGACTGACAAAATGCAAAG \\
\hline ScafBCA-F & GCTGCCATTGAAGCGGGCGGAGGTGGCTCTGGCGGTGGCGGATCGCGAATTCTGGCTATCG \\
\hline ScafBCA-R & GTGGTGGTGGTGGTGTTCTTGCCCGGAAGTTTCTTCCATGC \\
\hline
\end{tabular}

on a biosensor; changes in the reflected interference wave pattern between the sample and an internal reference layer result in a phase shift that can be followed in real time in both kinetic and quantitative modes [22]. All experiments were performed in kinetic buffer (20 mM PBS, pH 7.0;
$1 \mathrm{mg} / \mathrm{ml}$ bovine serum albumin (BSA), and $0.02 \%$ Tween $20)$. One of the proteins $(1 \mu \mathrm{M})$ was biotinylated by incubating with $2 \mu$ l biotinyl $\mathrm{N}$-hydroxysuccinimide ester for $1 \mathrm{~h}$ at room temperature, with excess biotin removed using a desalting column. The biotinylated protein was loaded 
onto the streptavidin biosensor by incubating for $240 \mathrm{~s}$. The immobilized protein was equilibrated with kinetic buffer for $180 \mathrm{~s}$, and the corresponding protein $(1 \mu \mathrm{M})$ was associated to the biotinylated protein by incubating for $800 \mathrm{~s}$. Dissociation was measured for $800 \mathrm{~s}$ in kinetic buffer. For each assay, a control experiment was carried out using BSA. Binding affinity was independent of which protein was loaded onto the streptavidin biosensor [23-26].

\section{Enzyme assays}

The BGL activity was measured by incubating $135 \mu \mathrm{l}$ of $2.5 \mathrm{mM}$ p-nitrophenyl $\beta$-D-glucopyranoside solution in $20 \mathrm{mM}$ sodium phosphate buffer $(\mathrm{pH} 7.0)$ with $7.5 \mu \mathrm{g}$ of pure enzyme solution at $37^{\circ} \mathrm{C}$ for $30 \mathrm{~min}$. The reaction was terminated by adding $70 \mu \mathrm{l}$ of $0.4 \mathrm{M} \mathrm{Na}_{2} \mathrm{CO}_{3}$ and the absorbance at $420 \mathrm{~nm}$ was measured. One unit of enzyme was defined as the activity producing $1 \mu \mathrm{mol}$ of p-nitrophenol per min under the assay conditions. EG/ $\mathrm{CBH}$ activity was measured by incubating $90 \mu \mathrm{l}$ of $1.5 \%$ (wt/vol) carboxymethyl cellulose (CMC) in $20 \mathrm{mM}$ sodium phosphate buffer ( $\mathrm{pH} 7.0$ ) with $5 \mu \mathrm{g}$ of pure enzyme solution at $37^{\circ} \mathrm{C}$ for $30 \mathrm{~min}$. A $100-\mu \mathrm{l}$ volume of sample was mixed with $150 \mu \mathrm{l}$ of 3,5-dinitrosalicylic acid reagent, and after boiling for $10 \mathrm{~min}$, the absorbance at $540 \mathrm{~nm}$ was measured. One unit of enzymatic activity was defined as the amount of enzyme required to produce a $1 \mu \mathrm{mol}$ reduction sugar per min under the assay conditions.

The activity of free or assembled enzymes was assayed in the presence of $0.75 \%$ (wt/vol) $\mathrm{CMC}$ at $37^{\circ} \mathrm{C}$ in $20 \mathrm{mM}$ sodium phosphate buffer ( $\mathrm{pH}$ 7.0). The reduction sugars were measured as described above. Glucose concentration was determined using an SBA biosensor analyzer (Biology Institute of Shandong Academy of Sciences, Jinan, China).

\section{Results and discussion}

\section{Selection and characterization of interacting proteins}

To synthesize the protein scaffold, three pairs of interacting proteins from E. coli $\mathrm{K} 12$ were expressed in E. coli BL21 (DE3). The six proteins were purified by Ni-chelating affinity chromatography (Figure $2 \mathrm{~A}$ ), and protein-protein affinity was measured by biolayer interferometry [23-26], in which the obtained values reflect the amount of protein bound to the biosensor. The response values (Figure 2B,C, D) confirmed their binding, and the $K_{D}$ calculated by Fortebio Data Analysis software version 7.0 for IPA-IPa $\left(7.36 \times 10^{-8} \mathrm{M}\right)$, IPB-IPb $\left(1.39 \times 10^{-12} \mathrm{M}\right)$, and IPC-IPC $\left(5.27 \times 10^{-8} \mathrm{M}\right)$ demonstrated their high affinity, suggesting that they are suitable for constructing protein scaffolds.
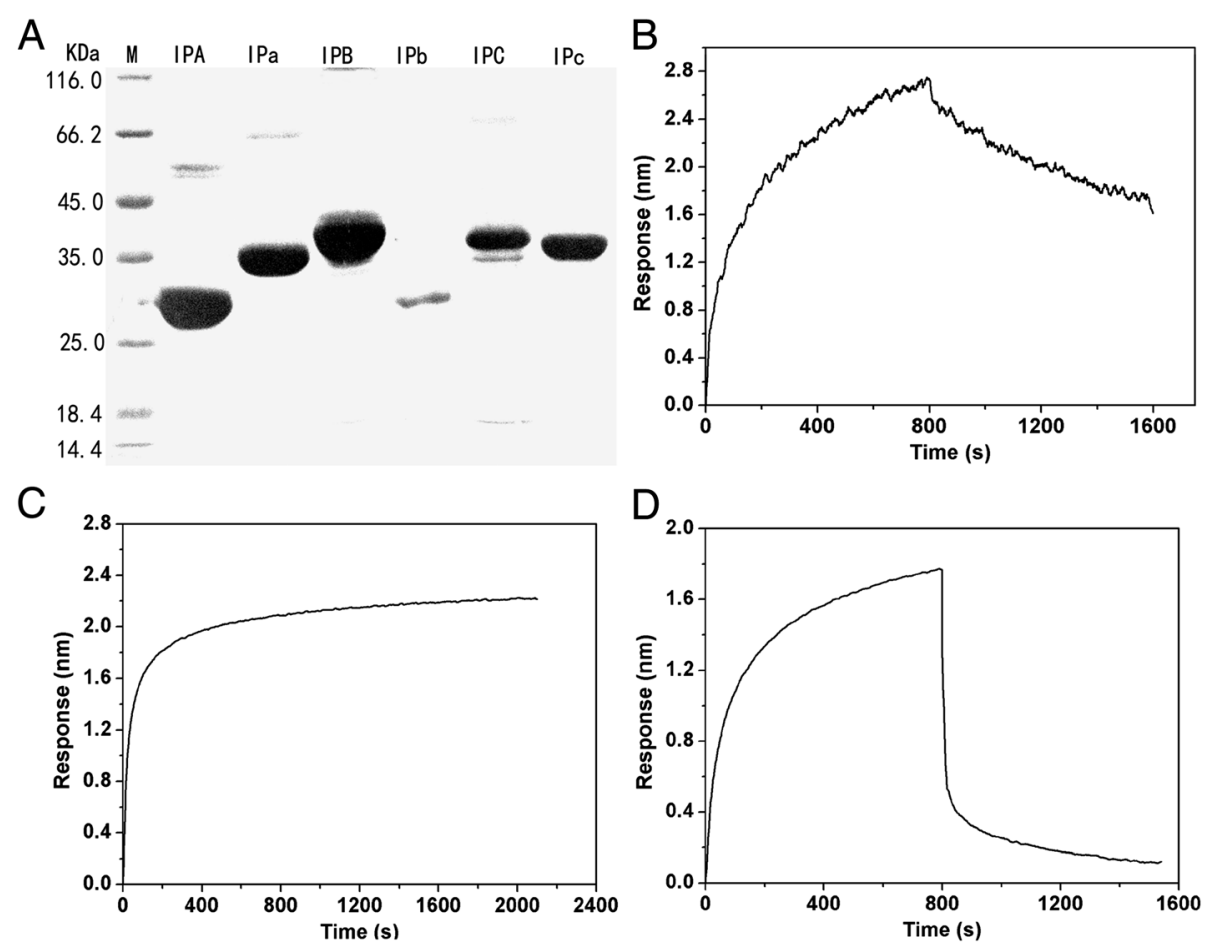

Figure 2 Purification of interaction proteins and their binding affinity. (A) SDS-PAGE analysis of purified interaction proteins. Biolayer interferometry sensorgrams of (B) IPA-IPa, (C) IPB-IPb, (D) IPC-IPC. IPA, IPB, and IPC were immobilized to the streptavidin-coated biosensors, respectively. Then $\mathrm{IPa}, \mathrm{IPb}$, and $\mathrm{IPC}$ were bound to the corresponding proteins, respectively. The figure shows the response of association and dissociation. All the response value was normalized by minusing the value of control. 


\section{Fusion of cellulases and interacting proteins}

The three cellulases were fused with the interacting proteins $\mathrm{IPa}, \mathrm{IPb}$, and IPc, which endowed them with an interaction interface. To minimize the effect of fusion on enzymatic activity, six fusion proteins were generated by attaching the interacting proteins to the $\mathrm{C}$ or $\mathrm{N}$ terminus of cellulases. The commonly used glycine-serine linker $\left(\mathrm{G}_{4} \mathrm{~S}\right)_{2}$ was used to link two proteins and thereby reduce folding interference [27]. The resultant constructs were expressed in E. coli with a 6-histidine tag at the $\mathrm{N}$ terminus and purified by $\mathrm{Ni}$-chelating affinity chromatography. IPa could only be attached to the $\mathrm{N}$ terminus of celCCA (IPaA) (Figure 3A), given that partial proteolysis occurred at the $\mathrm{C}$ terminus [19]. Similarly, the ideal celCCE and IPb fusion was obtained by attaching $\mathrm{IPb}$ to the $\mathrm{N}$ terminus of celCCE (IPbE). For the cel2454-IPc fusion, the activity of IPc4 was slightly higher than that of 4IPc (Figure 3D), and the former was therefore chosen for the assembly. The three enzyme fusions that were ultimately selected retained almost all of the specific activity of the respective unfused proteins (Figure 3B,C,D), indicating that protein structure was not appreciably compromised by the fusion.

\section{Construction of scaffolds and their effect on assembled enzyme complexes}

To determine the appropriate order of cellulases within assemblies, three protein scaffolds were constructed by fusing the three interacting proteins (IPA, IPB, and IPC) in different orders and assembling three tri-enzyme complexes by mixing the scaffolds and cellulases in a 1:1:1:1 stoichiometry for $1 \mathrm{~h}$. The reduction sugars from CMC hydrolysis catalyzed by the three tri-enzyme complexes were assayed. The complex assembled with ScafBAC had the highest sugar reduction (Figure 4), indicating that the synergistic effect was related to the location of the enzyme within the complex. Given that the activity of EG is much higher than that of $\mathrm{CBH}$ or $\mathrm{BGL}$, oligosaccharides and cellobioses produced by EG can be immediately catalyzed by $\mathrm{CBH}$ and $\mathrm{BGL}$ when EG is between $\mathrm{CBH}$ and BGL.

\section{Characterization of the tri-enzyme complex assembled by ScafBAC}

The fused cellulases and protein scaffold were purified using a Ni-sepharose column, and the correct formation of the protein assembly as well as the affinity of each cellulase fused to the protein scaffold was verified by biolayer interferometry [28] (Figure 5). The response of biolayer interferometry is dependent on the amount of proteins bound to the biosensor which indicates the binding of proteins. Although different binding responses were observed for the three cellulase fusions, they were all attached to the scaffold. Moreover, the binding responses were similar to values obtained for the interacting proteins, indicating that the binding affinity was not affected by the fusion.

The potential for synergistic effects on enzyme cascades is the most interesting property of protein assemblies. The
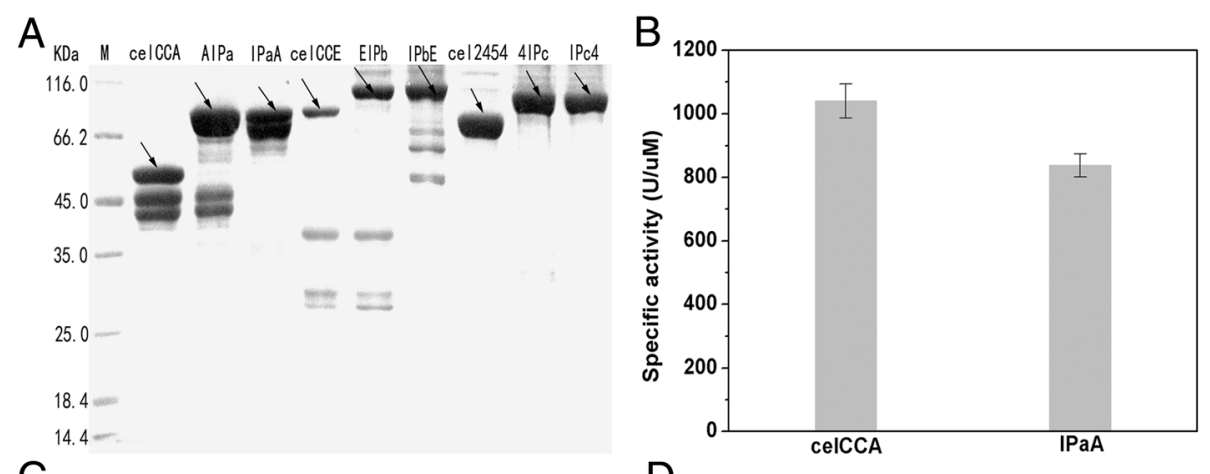

C
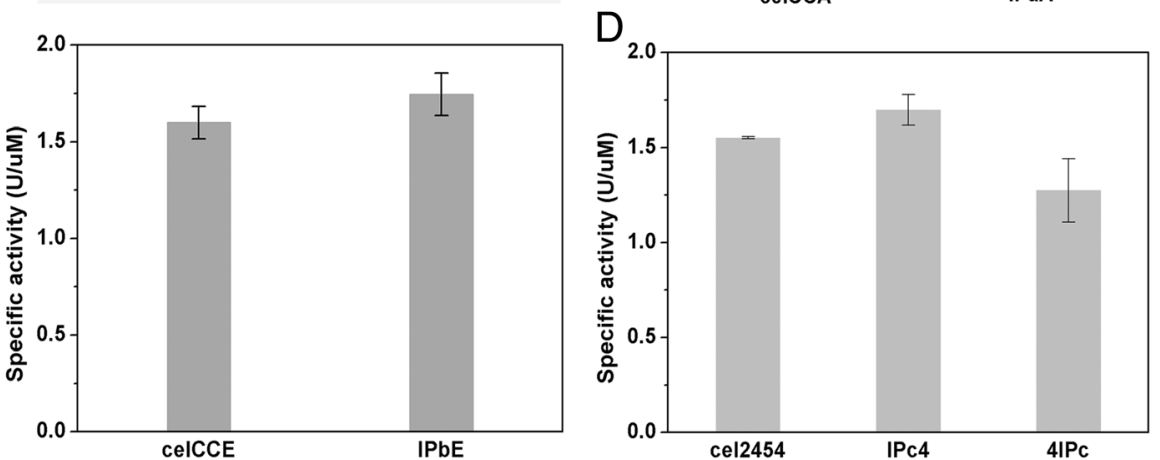

Figure $\mathbf{3}$ Characterization of cellulases fused with interaction proteins. (A) SDS-PAGE analysis of purified cellulases. The activities of (B) endoglucanase, (C) exoglucanase, (D) $\beta$-glucosidase were assayed. The arrows indicate the expected fusion proteins. 


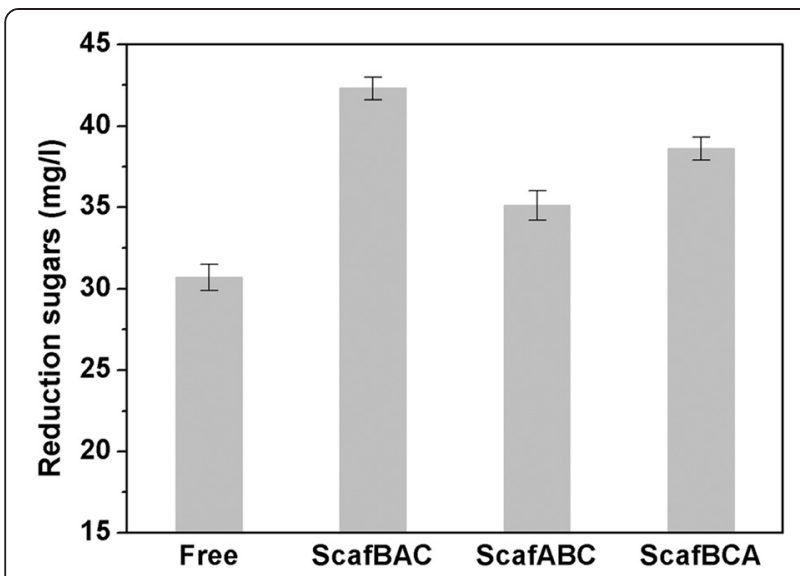

Figure 4 Reducing sugar production by free cellulases or three multienzyme complexes assembling with different scaffolds.

$1.5 \mathrm{~g} / \mathrm{l}$ of CMC was catalyzed by 0.6 MM of enzyme for 30 min. 'Free' means three fusion cellulases without scaffolds.

capacity for CMC hydrolysis was compared between the tri-enzyme complex and free cellulases. Catalytic activity was evaluated by glucose production using a SBA biosensor analyzer. After a 4-h reaction, a 1.5-fold enhancement in activity was observed for the tri-enzyme complex as compared to the corresponding free enzymes (Figure 6), suggesting the channeling of intermediates within the complex; that is, cellobiose generated by EG and CBH was immediately transferred to the adjacent BGL for glucose production, thereby resulting in enhanced cellulose hydrolysis.

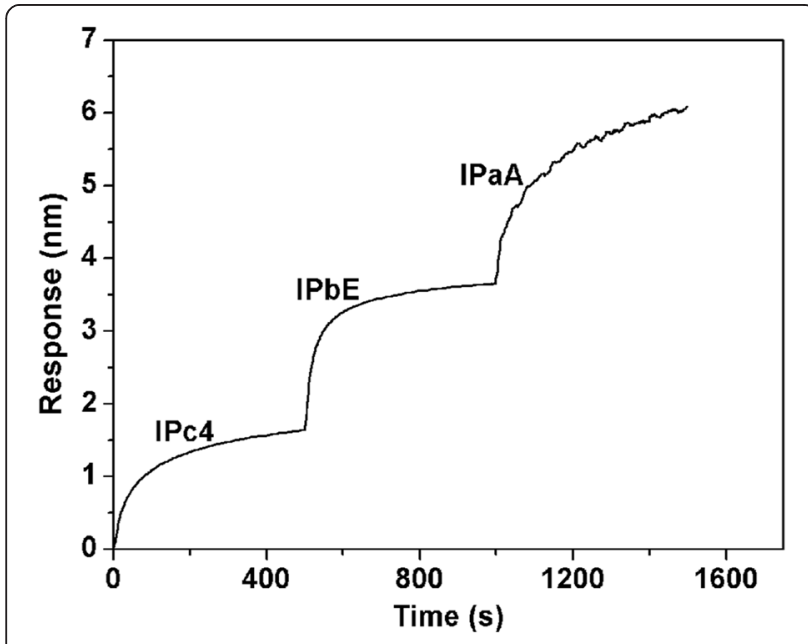

Figure 5 Biolayer interferometry sensorgrams of cellulases binding to biotinylated scaffold on streptavidin-coated biosensors.

Biotinylated scaffold was immobilized to the streptavidin-coated biosensors. Then IPc4, IPbE, and IPaA were bound to the scaffold. The figure shows the response of association with IPc4, IPbE, and IPaA. All the response value was normalized by minusing the value of control.

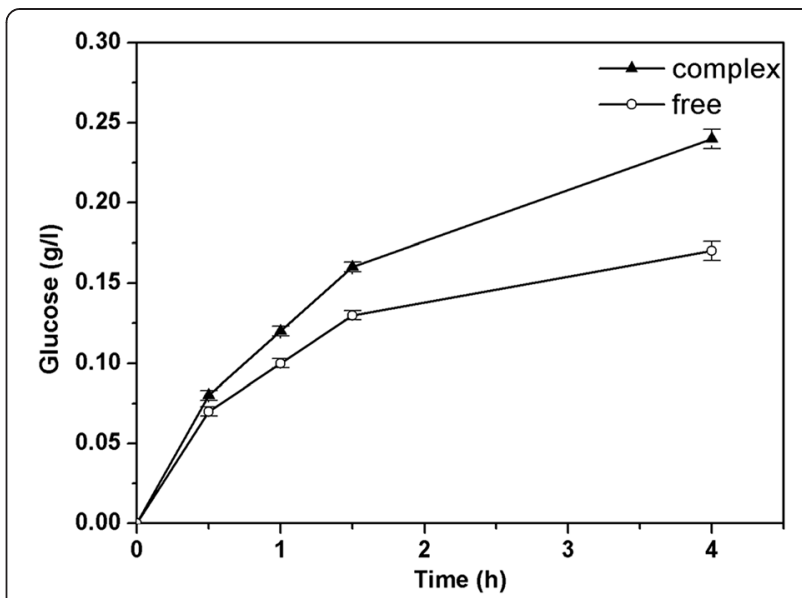

Figure 6 Glucose production of catalyzed by multienzyme complex or by equal amount of free cellulases. $7.5 \mathrm{~g} / \mathrm{l}$ of $\mathrm{CMC}$ was catalyzed by $0.6 \mu \mathrm{M}$ of enzyme. 'Free' means three fusion cellulases without scaffolds.

\section{Conclusions}

An artificial tri-enzyme complex was constructed by assembling three cellulases with a novel protein scaffold composed of interacting proteins. The effect of the order of cellulase within the scaffolds on the catalytic efficiency was determined. Moreover, the complex had higher catalytic activity than the individual components. These results suggest that this novel protein scaffold can serve as a powerful tool for facilitating multienzyme cascades.

\section{Competing interests}

The authors declare that they have no competing interests.

\section{Authors' contributions}

TY carried out the experiment and drafted the manuscript. XG participated in the design of the study and revised the manuscript. YR and DW conceived of the study, participated in its design and coordination. All authors read and approved the final manuscript.

\section{Acknowledgements}

This work supported by National Special Fund for State Key Laboratory of Bioreactor Engineering (2060204), and 'the Fundamental Research Funds for the Central Universities', People's Republic of China.

Received: 18 December 2014 Accepted: 15 March 2015 Published online: 01 April 2015

\section{References}

1. Ricca E, Brucher B, Schrittwieser JH (2011) Multi-enzymatic cascade reactions: overview and perspectives. Advan Synthesis Catalysis 353(13):2239-2262

2. Conrado RJ, Varner JD, DeLisa MP (2008) Engineering the spatial organization of metabolic enzymes: mimicking nature's synergy. Curr Opin Biotechnol 19(5):492-499

3. Schoffelen S, van Hest JCM (2012) Multi-enzyme systems: bringing enzymes together in vitro. Soft Matter 8(6):1736-1746

4. Adlakha N, Sawant S, Anil A, Lali A, Yazdani SS (2012) Specific fusion of beta-1,4-endoglucanase and beta-1,4-glucosidase enhances cellulolytic activity and helps in channeling of intermediates. Appl Environ Microbiol 78 (20):7447-7454

5. Schoffelen S, Beekwilder J, Debets MF, Bosch D, van Hest JC (2013) Construction of a multifunctional enzyme complex via the strain-promoted azide-alkyne cycloaddition. Bioconjug Chem 24(6):987-996 
6. Fu J, Liu M, Liu Y, Woodbury NW, Yan H (2012) Interenzyme substrate diffusion for an enzyme cascade organized on spatially addressable DNA nanostructures. J Am Chem Soc 134(12):5516-5519

7. Sun Q, Madan B, Tsai SL, DeLisa MP, Chen W (2014) Creation of artificial cellulosomes on DNA scaffolds by zinc finger protein-guided assembly for efficient cellulose hydrolysis. Chem Commun (Camb) 50(12):1423-1425

8. Dueber JE, Wu GC, Malmirchegini GR, Moon TS, Petzold CJ, Ullal AV, Prather KL, Keasling JD (2009) Synthetic protein scaffolds provide modular control over metabolic flux. Nat Biotechnol 27(8):753-759

9. You C, Myung S, Zhang YH (2012) Facilitated substrate channeling in a self-assembled trifunctional enzyme complex. Angew Chem Int Ed Engl 51 (35):8787-8790

10. Hirakawa H, Nagamune T (2010) Molecular assembly of P450 with ferredoxin and ferredoxin reductase by fusion to PCNA. ChemBioChem 11 (11):1517-1520

11. Liu F, Banta S, Chen W (2013) Functional assembly of a multi-enzyme methanol oxidation cascade on a surface-displayed trifunctional scaffold for enhanced NADH production. Chem Commun (Camb) 49(36):3766-3768

12. Tsai SL, DaSilva NA, Chen W (2013) Functional display of complex cellulosomes on the yeast surface via adaptive assembly. ACS Synth Biol 2(1):14-21

13. Borne R, Bayer EA, Pages S, Perret S, Fierobe HP (2013) Unraveling enzyme discrimination during cellulosome assembly independent of cohesin-dockerin affinity. FEBS J 280(22):5764-5779

14. Fan LH, Zhang ZJ, Yu XY, Xue YX, Tan TW (2012) Self-surface assembly of cellulosomes with two miniscaffoldins on Saccharomyces cerevisiae for cellulosic ethanol production. Proc Natl Acad Sci U S A 109(33):13260-13265

15. Geddes CC, Nieves IU, Ingram LO (2011) Advances in ethanol production. Curr Opin Biotechnol 22(3):312-319

16. Rizk M, Antranikian G, Elleuche S (2012) End-to-end gene fusions and their impact on the production of multifunctional biomass degrading enzymes. Biochem Biophys Res Commun 428(1):1-5

17. Liu M, Yu H (2012) Co-production of a whole cellulase system in Escherichia coli. Biochem Eng J 69:204-210

18. Levchenko A, Hu P, Janga SC, Babu M, Díaz-Mejía JJ, Butland G, Yang W, Pogoutse O, Guo X, Phanse S, Wong P, Chandran S, Christopoulos C, Nazarians-Armavil A Nasseri NK, Musso G, Ali M, Nazemof N, Eroukova V, Golshani A, Paccanaro A, Greenblatt JF, Moreno-Hagelsieb G, Emili A (2009) Global functional atlas of Escherichia coli encompassing previously uncharacterized proteins. PLoS Biol 7(4):e1000096

19. Fierobe HP, Gaudin C, Belaich A, Loutfi M, Faure E, Bagnara C, Baty D, Belaich JP (1991) Characterization of Endoglucanase A from Clostridium cellulolyticum. J Bacteriol 173(24):7956-7962

20. Gaudin C, Belaich A, Champ S, Belaich JP (2000) CelE, a multidomain cellulase from Clostridium cellulolyticum: a key enzyme in the cellulosome. J Bacteriol 182:1910-1915

21. You C, Zhang XZ, Zhang YH (2012) Simple cloning via direct transformation of PCR product (DNA multimer) to Escherichia coli and Bacillus subtilis. Appl Environ Microbiol 78(5):1593-1595

22. Naik S, Kumru OS, Cullom M, Telikepalli SN, Lindboe E, Roop TL, Joshi SB, Amin D, Gao P, Middaugh CR, Volkin DB, Fisher MT (2014) Probing structurally altered and aggregated states of therapeutically relevant proteins using GroEL coupled to bio-layer interferometry. Protein Sci 23(10):1461-1478

23. Fierobe HP, Mingardon F, Mechaly A, Belaich A, Rincon MT, Pages S, Lamed R, Tardif C, Belaich JP, Bayer EA (2005) Action of designer cellulosomes on homogeneous versus complex substrates: controlled incorporation of three distinct enzymes into a defined trifunctional scaffolding. J Biol Chem 280(16):16325-16334

24. Wei ZH, Chen H, Zhang C, Ye BC (2014) FRET-based system for probing protein-protein interactions between sigma(R) and RsrA from Streptomyces coelicolor in response to the redox environment. PloS One 9(3):e92330

25. Prischi F, Konarev PV, lannuzzi C, Pastore C, Adinolfi S, Martin SR, Svergun DI, Pastore A (2010) Structural bases for the interaction of frataxin with the central components of iron-sulphur cluster assembly. Nat Commun 1(95):1-10

26. Maun HR, Wen X, Lingel A, de Sauvage FJ, Lazarus RA, Scales SJ, Hymowitz SG (2010) Hedgehog pathway antagonist 5E1 binds hedgehog at the pseudo-active site. J Biol Chem 285(34):26570-26580
27. Lu P, Feng MG (2008) Bifunctional enhancement of a beta-glucanasexylanase fusion enzyme by optimization of peptide linkers. Appl Microbiol Biotechnol 79(4):579-587

28. Smith MC, Scaglione KM, Assimon VA, Patury S, Thompson AD, Dickey CA Southworth DR, Paulson HL, Gestwicki JE, Zuiderweg ER (2013) The E3 ubiquitin ligase CHIP and the molecular chaperone Hsc70 form a dynamic tethered complex. Biochemistry 52(32):5354-5364

\section{Submit your manuscript to a SpringerOpen ${ }^{\odot}$ journal and benefit from:}

- Convenient online submission

- Rigorous peer review

- Immediate publication on acceptance

- Open access: articles freely available online

- High visibility within the field

- Retaining the copyright to your article

Submit your next manuscript at $>$ springeropen.com 